\title{
Monitoring compliance with sulfur content regulations of shipping fuel by in situ measurements of ship emissions
}

\author{
L. Kattner ${ }^{1,2}$, B. Mathieu-Üffing ${ }^{1,2}$, J. P. Burrows ${ }^{1}$, A. Richter ${ }^{1}$, S. Schmolke ${ }^{2}$, A. Seyler ${ }^{1}$, and F. Wittrock ${ }^{1}$ \\ ${ }^{1}$ Institute for Environmental Physics, University of Bremen, Germany \\ ${ }^{2}$ Federal Maritime and Hydrographic Agency, Hamburg, Germany \\ Correspondence to: L. Kattner (lisa.kattner@bsh.de)
}

Received: 12 March 2015 - Published in Atmos. Chem. Phys. Discuss.: 15 April 2015

Revised: 3 August 2015 - Accepted: 13 August 2015 - Published: 9 September 2015

\begin{abstract}
In 1997 the International Maritime Organisation (IMO) adopted MARPOL Annex VI to prevent air pollution by shipping emissions. It regulates, among other issues, the sulfur content in shipping fuels, which is transformed into the air pollutant sulfur dioxide $\left(\mathrm{SO}_{2}\right)$ during combustion. Within designated Sulfur Emission Control Areas (SECA), the sulfur content was limited to $1 \%$, and on 1 January 2015, this limit was further reduced to $0.1 \%$. Here we present the set-up and measurement results of a permanent ship emission monitoring site near Hamburg harbour in the North Sea SECA. Trace gas measurements are conducted with in situ instruments and a data set from September 2014 to January 2015 is presented. By combining measurements of carbon dioxide $\left(\mathrm{CO}_{2}\right)$ and $\mathrm{SO}_{2}$ with ship position data, it is possible to deduce the sulfur fuel content of individual ships passing the measurement station, thus facilitating the monitoring of compliance of ships with the IMO regulations. While compliance is almost $100 \%$ for the 2014 data, it decreases only very little in 2015 to $95.4 \%$ despite the much stricter limit. We analysed more than 1400 ship plumes in total and for months with favourable conditions, up to $40 \%$ of all ships entering and leaving Hamburg harbour could be checked for their sulfur fuel content.
\end{abstract}

\section{Introduction}

Shipping is a major part of the global transportation sector and its importance is still growing. According to the United Nations Conference on Trade and Development's Review of Maritime Transport, in 2013 a total of 9.6 billion tons were transported via ships. This corresponds to a growth rate of this sector of $3.8 \%$ per year (UNCTAD, 2014). Despite being the most efficient and least emitting mode of transportation per ton of cargo compared to land-based or airborne transport, shipping emissions nevertheless are a considerable fraction of total anthropogenic emissions and have a significant impact on the air quality of coastal areas. $70 \%$ of shipping emissions are produced within $400 \mathrm{~km}$ off the coasts (Corbett et al., 1999) and can cause severe health and environmental problems to these regions (Corbett et al., 2007; Eyring et al., 2010).

The International Maritime Organisation (IMO), an agency of the UN with 171 member states, has decided on measures to limit the impact of shipping emissions by adopting MARPOL Annex VI in 1997. One part of these measures, and on which this study focuses, is the reduction of sulfur in ship fuel in order to reduce sulfur dioxide $\left(\mathrm{SO}_{2}\right)$ emissions. When oxidised, $\mathrm{SO}_{2}$ forms small sulfate particles, which have an effect on cloud properties and change their reflectivity and lifetime (Lauer et al., 2007). $\mathrm{SO}_{2}$ emissions by ships lead to an enhanced sulfate concentration of 10-50\% in coastal areas (Matthias et al., 2010), which increases acidification by acid rain (Endresen et. al., 2003). Gaseous $\mathrm{SO}_{2}$ as well as sulfate particles have health effects on humans, when inhaled. $\mathrm{SO}_{2}$ is produced during the combustion process by burning sulfur that is contained in the fuel. Ship engines have been developed to be able to burn heavy fuel oils (HFO) that have a very high sulfur content of up to several percent and are basically a waste product of oil refineries and thus very cheap.

The IMO regulations concerning sulfur content came into force in 2005 and were revised in 2008; the revision came into force in 2010. For all oceans worldwide, the sulfur con- 
tent allowed in HFOs was capped at $4.5 \%$, and after 2012 this limit was reduced to $3.5 \%$. In addition, so-called "Sulfur Emission Control Areas" (SECA) were established with an even further reduced sulfur limit. One SECA is along the North American coast, and another one comprises the Baltic Sea and the North Sea up to the Shetland Islands and to the western entrance of the English Channel. Within these SECAs the sulfur limit was initially set to $1.5 \%$, which was reduced to $1.0 \%$ in 2010 and has now reached its current reduction step in January 2015 with a limit of $0.1 \%$.

While the $1 \%$ limit could still be met with sulfur-reduced HFO, the new regulation forces ships to either use more expensive alternatives such as marine gas oil (MGO), or ultralow sulfur HFO, or consider reconstruction to enable the use of alternative fuel such as liquefied natural gas (LNG) or methanol. As an alternative technology, the operation of exhaust gas cleaning systems (scrubbers) is also permitted, as long as it provides the same level of protection against sulfur dioxide emissions as the use of low sulfur fuel. These alternative options have been deployed to some ships and first studies have documented their effectiveness and economic efficiency (Reynolds, 2011; Jiang et al., 2014), but they are still under development and not very widespread, and for the vast majority of ships, the only option to meet the regulations is to use desulfurised fuel.

With the regulations in place, the question remains on how to efficiently verify compliance of the ships. To date, compliance is checked by inspection authorities who enter ships at berth, review fuel log books and fuel quality certificates and, if suspicion is raised, take a fuel sample to be analysed at certified laboratories. With the results of these analyses, it is possible to verify compliance and if needed, take legal action. However, these controls can check just a minor number of ships. It is also not possible to evaluate the performance and compliance of scrubber technology by sulfur prediction in bunker oil samples which would be problematic if this method becomes more popular and common in future. Another problem is to control ship fuel of ships on the open sea.

For these reasons, several studies have suggested the implementation of air quality measurement systems especially aiming at the surveillance of ship emissions. One simple but efficient method is direct and simultaneous measurements of pollution trace gases with in situ instruments. These instruments can quite easily be adapted to measurement conditions on aeroplanes, research vessels and trucks and have been used in a variety of campaigns in recent years (Sinha et al., 2003; Schlager et al., 2006; Agrawal et al., 2009; Williams et al., 2009; Diesch et al., 2013; Balzani Lööv et al., 2014; Beecken et al., 2015). Based on the experience from those studies, we have established a measurement station near the harbour of Hamburg to monitor ship emissions, in order to estimate sulfur contents of fuel on board of passing individual ships. Our ship emissions data set from September 2014 to January 2015 documents the quality of implementation of the MARPOL VI regulation with respect to compliant sul-

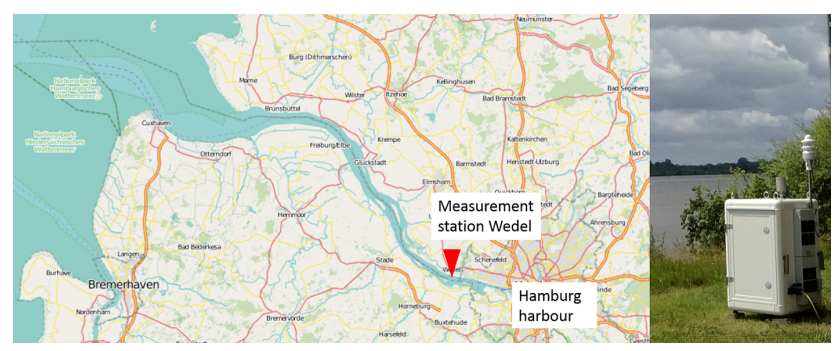

Figure 1. Location of the measurement station on the northern bank of the river Elbe, near Hamburg harbour. On the right: picture of instrument box. Map source: OpenStreetMap.

fur content in shipping fuel used in SECAs and follows the recent strong tightening of the regulation on 1 January 2015.

\section{Measurement site and methods}

The measurements reported here were conducted as part of the Mesmart project, a cooperation between the University of Bremen and the German Federal Maritime and Hydrographic Agency.

\subsection{Measurement site}

Hamburg harbour is the third largest harbour in Europe and the 14th largest worldwide. In 2014, it had a 20-foot standard container throughput of 9.7 billion containers according to Hamburg port statistics. On average there are 800 calls per month, of which more than half are container vessels, and the other half consists mainly of reefer vessels, tankers and bulk carriers. The harbour is located at the mouth of the river Elbe about $110 \mathrm{~km}$ inland; see Fig. 1.

Measurements were conducted next to the river Elbe in the town of Wedel, which is near Hamburg, on the property and with the support of the Waterways and Shipping Office Hamburg. The instruments were set up right at the northern banks of the Elbe, with an approximate line of sight distance to ships leaving and entering Hamburg harbour of 0.3 and $0.5 \mathrm{~km}$ respectively. The average main wind direction at this location has a southerly component, so for most of the time within the measurement period, the exhaust plumes of the ships were blown to the instruments. The area in the main wind direction south of the measurement station and the Elbe is rural and sparsely populated with no significant sources of air pollution. Thus the location of the monitoring site is optimal for relatively low background concentrations of nitrogen oxides $\left(\mathrm{NO}_{x}\right)$ and $\mathrm{SO}_{2}$.

\subsection{Instrumentation}

The concentrations of $\mathrm{SO}_{2}, \mathrm{NO}_{x}, \mathrm{CO}_{2}$ and ozone $\left(\mathrm{O}_{3}\right)$ were measured continuously with individual instruments, which were combined in a temperature-stabilised box to ensure sta- 
ble measurement conditions and at the same time provide a compact and transportable set-up. Data were stored in an integrated data logger with the time resolution of $1 \mathrm{~min}$. Despite different time resolutions of the instruments, we used data normalised to $1 \mathrm{~min}$, which is sufficient for the analysis of emission events with a duration in the order of several minutes.

$\mathrm{NO}_{x}, \mathrm{SO}_{2}$ and $\mathrm{O}_{3}$ were measured with instruments from the Horiba AP-370 series, which are certified instruments according to EU directives (EN14211 for $\mathrm{NO}_{x}$, EN 14212 for $\mathrm{SO}_{2}$ and $\mathrm{EN} 14625$ for $\mathrm{O}_{3}$ ) used by German authorities for standard air pollution measurements. $\mathrm{CO}_{2}$ was measured with a Licor 840A analyser. The $\mathrm{O}_{3}$ measurements were not used for this study and are just mentioned for completeness.

For $\mathrm{SO}_{2}$ : the Horiba APSA-370 is based on the UVfluorescence method, using the excitation of $\mathrm{SO}_{2}$ molecules by UV light and measuring the fluorescence which is a function of $\mathrm{SO}_{2}$ concentration. The response time of the instrument is specified to be less than $120 \mathrm{~s}$. Calibration was carried out with a standard gas mixture from Air Liquide with

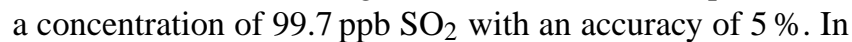
addition, a daily control was obtained by the measurement of zero gas produced with a scrubber, and span gas from an internal permeation source with $175 \mathrm{ppb} \mathrm{SO}_{2}$. There is a NO cross sensitivity for $\mathrm{SO}_{2}$ which gives an $\mathrm{SO}_{2}$ signal for $0.8 \%$ of the NO signal. We have determined this value of $0.8 \%$ via a set of six calibration measurements of different NO concentrations between 100 and $470 \mathrm{ppb}$.

For $\mathrm{NO}_{x}$ : the Horiba APNA-370 measures the chemiluminescence of $\mathrm{NO}$ molecules reacting with $\mathrm{O}_{3}$. To obtain information about the $\mathrm{NO}_{2}$ concentration, the device contains a deoxidation converter to transfer $\mathrm{NO}_{2}$ molecules to $\mathrm{NO}$. The $\mathrm{NO}_{2}$ concentration is calculated by the difference of total $\mathrm{NO}_{x}$, representing $\mathrm{NO}+\mathrm{NO}_{2}$, and $\mathrm{NO}$ without conversion. The response time for measurement of both gases is $90 \mathrm{~s}$. The instrument is calibrated with an Air Liquide standard gas mixture with a concentration of $216.0 \mathrm{ppb} \mathrm{NO}$ and an accuracy of $5 \%$. A daily control with scrubber-produced zero gas and an $\mathrm{NO}_{2}$ span gas of $105 \mathrm{ppb}$ is also implemented.

For $\mathrm{CO}_{2}$ : the Licor $840 \mathrm{~A}$ is a non-dispersive infrared gas analyser. It has a response time of $1 \mathrm{~s}$ and was calibrated with two Air Liquide standard gas mixtures with 306.6 and 990.0 ppm $\mathrm{CO}_{2}$ with an accuracy of $2 \%$.

The trace gas measurements were complemented with measurements of wind, temperature, air pressure and precipitation by a compact weather station (Lufft WS600). With an AIS (automatic identification system) receiver the information transmitted by passing ships was collected, which includes identification number, name and type of the ship as well as position, course and speed.

\section{Data analysis}

To obtain the sulfur content of ship fuel in use, the enhancement of $\mathrm{SO}_{2}$ and $\mathrm{CO}_{2}$ in measurements affected by exhaust gases is measured, and the ratio of these $\mathrm{SO}_{2}$ and $\mathrm{CO}_{2}$ peaks is used to calculate the fuel sulfur content. The combination of the trace gas peak time, the wind direction and the AIS information enables the identification of the peak-related ship.

When wind conditions are favourable for measurements, the plumes of ships passing the instrument leave a distinctive enhancement of the measured component against background concentrations. Since this enhancement is most significant in NO measurements, and NO is an indicator for recent combustion processes, these NO peaks are used to identify the time stamp of a ship emission event. For these time stamps, peaks in $\mathrm{CO}_{2}$ are then identified, which is more complicated because background concentrations are larger and more variable due to the surrounding vegetation. Background signals for each gas are determined via a customised running mean filter. The $\mathrm{SO}_{2}$ signals are only analysed for those events for which there was a significant $\mathrm{CO}_{2}$ peak and a clearly determinable background. For all peaks the individual peak area above the background concentration is determined. This accounts for the difference in peak width for each gas due to different time resolutions of the respective instruments. The peak area value of the $\mathrm{SO}_{2}$ peaks is corrected with $0.8 \%$ of the peak area value of the NO peaks to account for the cross sensitivity. With the assumption that fuel contains $87 \pm 1.5 \%$ carbon (Cooper et al., 2003) and $100 \%$ of the sulfur and the carbon content of the fuel are emitted as $\mathrm{SO}_{2}$ and $\mathrm{CO}_{2}$ respectively, the sulfur fuel content (SFC) mass percent can be calculated as follows:

$$
\begin{aligned}
\operatorname{SFC}[\%] & =\frac{\mathrm{S}[\mathrm{kg}]}{\text { fuel }[\mathrm{kg}]} \\
& =\frac{\mathrm{SO}_{2}[\mathrm{ppm}] \cdot \mathrm{A}(\mathrm{S})}{\mathrm{CO}_{2}[\mathrm{ppm}] \cdot \mathrm{A}(\mathrm{C})} \cdot 87[\%] \\
& =\frac{\mathrm{SO}_{2}[\mathrm{ppb}]}{\mathrm{CO}_{2}[\mathrm{ppm}]} \cdot 0.232[\%],
\end{aligned}
$$

where $\mathrm{A}(\mathrm{S})$ is the atomic weight of sulfur and $\mathrm{A}(\mathrm{C})$ the atomic weight of carbon. Using this formula, it is relatively simple to calculate the sulfur content for each set of peaks. For a discussion about the uncertainties of this formula see Sect. 3.1.

The second part of the data analysis is the attribution of the identified emission events to individual passing ships. Within 30 min before each event, which is characterised by the time the emissions arrive at the instruments, the AIS data are analysed for ship positions close to the measurement site. In combination with wind information, this yields the identification of the individual ships which have caused the emission in most cases. The time the plume travels from being emitted to being analysed is about 2 to $10 \mathrm{~min}$, depending on wind speed and direction. However, there are events in which there 
are two or more ships too close to each other, or where no AIS signal was received, such that no single ship can be associated to the signal. These events are excluded from the data set.

\subsection{Uncertainties}

There are several aspects that influence the accuracy of the calculated values of the sulfur content for each ship. The SFC formula Eq. (1) assumes a $100 \%$ conversion from sulfur to $\mathrm{SO}_{2}$ during combustion, which is only true for an idealised combustion process. There is a range of uncertainty with respect to the amounts of sulfur oxidised and released as particles. Studies found that there could be an underestimation of the sulfur fuel content between 1 and $19 \%$ from assuming complete conversion (Schlager et al., 2006; Agrawal et al., 2008; Moldanova et al., 2009; Balzani Lööv et al., 2014).

The uncertainty or sum of systematic and random error of our measurements is determined from a combination of the calibration uncertainty and the uncertainty resulting from the signal to noise ratio (SNR). $\mathrm{CO}_{2}$ values with a SNR of less than 5 are excluded from the data, which leads to an upper limit uncertainty of $20 \%$. However, the majority of $\mathrm{CO}_{2}$ values have an uncertainty of around $10 \%$. For $\mathrm{SO}_{2}$ we do not exclude data with a low SNR because these are the zero sulfur content cases. The $\mathrm{SNR}$ of $\mathrm{SO}_{2}$ data for a sulfur content of around $0.1 \%$ is 10 or better, with a decrease for lower sulfur content values. For an SNR below 5 we consider the $\mathrm{SO}_{2}$ signal to be zero. This is only important for the January 2015 data, since the measured $\mathrm{SO}_{2}$ concentrations in 2015 are much lower than for the 2014 data. This is shown in Fig. 2 as a comparison between one week in December 2014 and one week in January 2015 with similar weather conditions. While no reduction in $\mathrm{NO}$ values can be observed, there is a large reduction in $\mathrm{SO}_{2}$ values, as expected.

All uncertainties added up with the root of sum of squares method; this gives us an uncertainty range for the sulfur content calculations of $15-30 \%$.

\section{Results}

Using the method described above we were able to identify 824 ship plumes of 474 individual ships within the months of September, November and December 2014. Unfortunately no data are available in October due to instrumentation problems. This data set is the so-called pre-regulation-change set, where the regulatory sulfur fuel content allowed for the ships of is $1.0 \%$. The January 2015 data set consists of 589 ship plumes of 374 individual ships, which since 1 January 2015 have to comply with the new $0.1 \%$ rule. As shown in Fig. 3, the difference between these two data sets is remarkably obvious.

In the pre-regulation-change data set, $99.6 \%$ of all ships complied with the $1 \%$ sulfur limit with respect to the mea- surement uncertainty. This is better than previously published compliance rates of $85 \%$ of 174 ship plumes (Beecken et al., 2014), although it should be noted that this study did not describe the uncertainty considerations and was measured by aeroplane on the open sea. The latter may imply that compliance might not be so high when no direct control is possible. Compliance rates at other locations for land-based measurements show values of $90 \%$ of 255 ship plumes and $97 \%$ of 211 ship plumes (Beecken et al., 2015). However, a study of Diesch et al., 2013, that describes measurements with a mobile laboratory along the Elbe River near our measurement site, found a compliance of nearly $100 \%$ for 139 ship plumes. This could possibly be credited to the special location of Hamburg harbour where ships have to go up the Elbe for more than $100 \mathrm{~km}$.

In accordance with the practice in use that fuel samples analysed in laboratories are considered as exceeding the $0.1 \%$ sulfur limit in a legally binding way above the value of $0.149 \%$, we suggest using a corresponding value of $0.15 \%$ as a limit value for discussing the compliance of the ships in our January 2015 data set. This is in consistence with the formerly stated measurement uncertainties. In Fig. 4, a more detailed graph of the January 2015 data is shown. The red line shows the $0.1 \%$ limit with the shaded area, indicating a conservative $30 \%$ measurement uncertainty. The blue line indicates the suggested $0.15 \%$ limit for compliance discussion. Of all the ships measured in January, $95.4 \%$ were complying with the new regulation. There are preliminary results for first SFC measurements in January 2015 presented in Beecken, 2015, which are comparable with our measurements, although with slightly higher uncertainty and lower compliance rates.

The lengths of the ships in $50 \mathrm{~m}$ size steps are colourcoded in Figs. 3 and 4. Even before the regulation change, ships smaller than $100 \mathrm{~m}$ did not use fuel with sulfur values higher than $0.2 \%$, most likely because their engines cannot process such fuels or because storage capacity for two different kinds of fuels is not available. After the regulation change, those smaller ships still do not use fuels that reach up to the $0.1 \%$ limit allowed. If one considers only those ships longer than $100 \mathrm{~m}$ that could choose which fuel to use and had to change their way of operation, the compliance drops to $93 \%$.

The number of ships that can be detected for compliance depends strongly on the wind conditions. Assuming the average number of calls in Hamburg harbour according to Hamburg port statistics of 800 ships per month means that 1600 emission events happen at our measurement station of ships on their way in and out of the harbour. For months with good wind conditions like December 2014 and January 2015, we can detect about $30-40 \%$ of those events, for months with unfavourable wind conditions, like November 2014, this value drops to less than $10 \%$. 

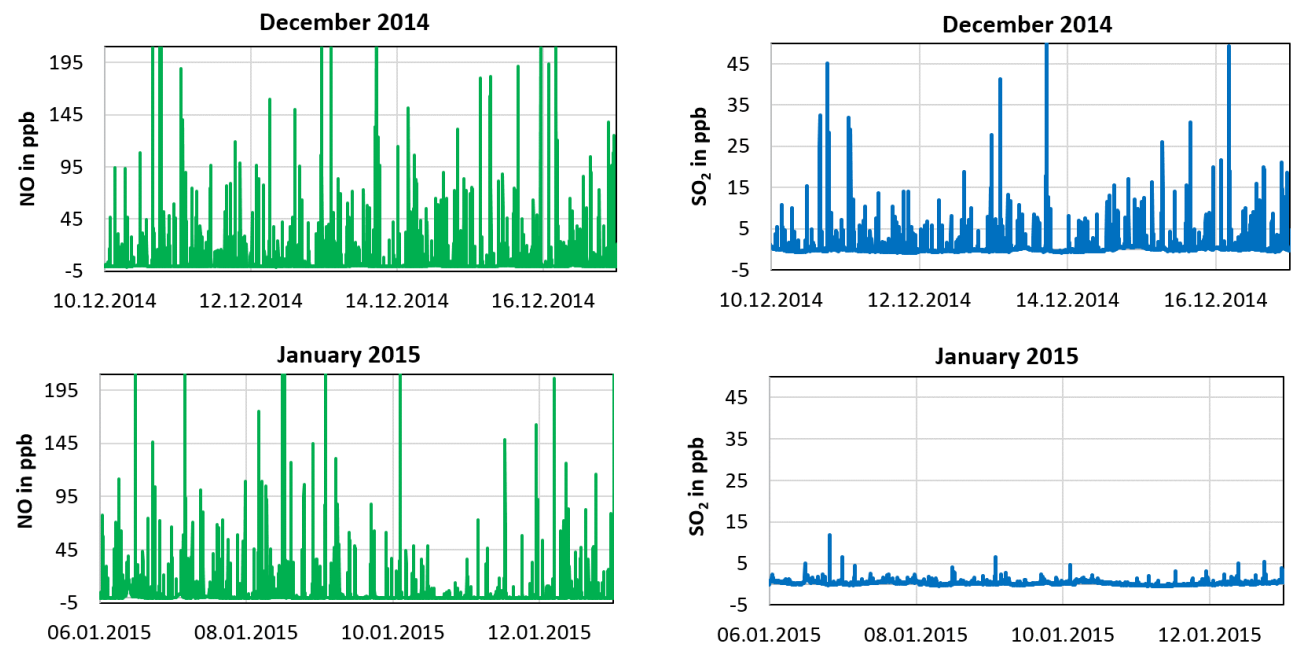

Figure 2. Comparison of absolute $\mathrm{NO}$ and $\mathrm{SO}_{2}$ volume mixing ratio values measured over 2 weeks, 1 week in December 2014 and 1 week in January 2015 with comparable wind conditions. Each peak belongs to one emission plume of an individual ship. The reduction in $\mathrm{SO}_{2}$ in 2015 is obvious, while for NO, no reduction can be observed.
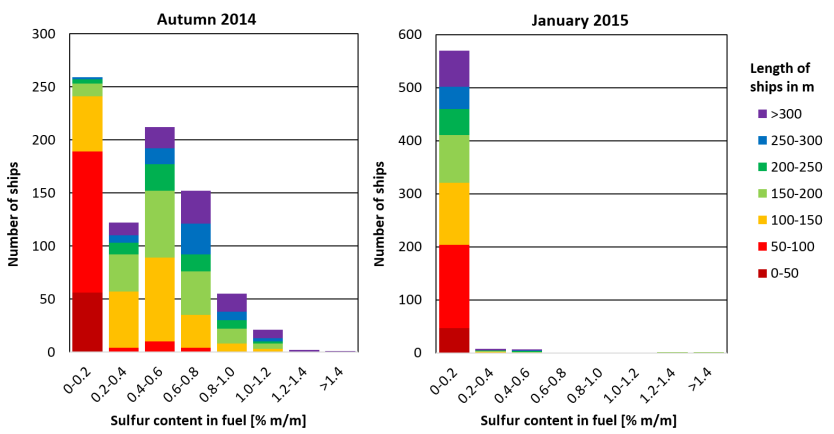

Figure 3. Sulfur fuel content in autumn 2014, and in January 2015, after the change of fuel regulations. The lengths of the ships that have been analysed are colour-coded. While in 2014 only small ships had fuel sulfur contents below $0.2 \%$, nearly all ships fell into this category in January 2015.

\section{Conclusions}

In this study, we have used the method of in situ measurements of trace gases to implement a system to monitor compliance of ships with sulfur fuel content regulations. This has been discussed and suggested before (Balzani Lööv et al., 2014). Here we present a suitable location for permanent stationary measurements near Hamburg harbour, one of the largest harbours in Europe, and demonstrate a measurement approach that successfully characterises emissions from passing ships. We describe the method used to identify ship emission events and the corresponding ships and present a large data set on fuel usage of ships of 1413 analysed ship plumes altogether. This includes one of the first data sets after the most recent regulation change in the North Sea SECA,

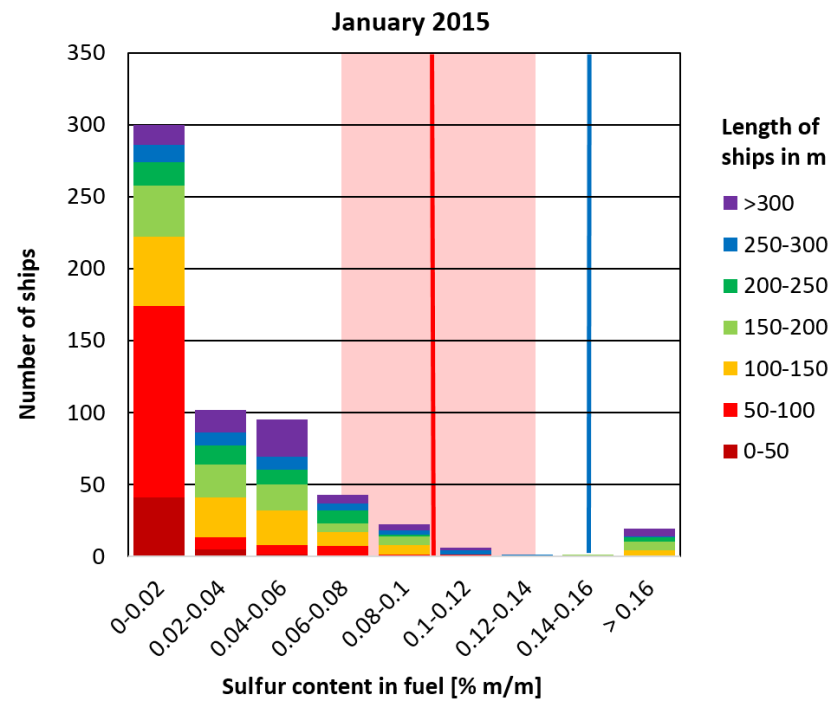

Figure 4. Detailed view of the January 2015 data set. The lengths of the ships are colour-coded; the red line indicates the $0.1 \%$ limit, with the shaded area representing the upper limit uncertainty of $30 \%$. The blue line indicates the suggested limit of $0.15 \%$ for flagging ships as exceeding the sulfur fuel content limit allowed.

where fuel sulfur content limits were reduced from 1 to $0.1 \%$ on 1 January 2015.

Our data show that the vast majority $(95.4 \%)$ of all the ships we have measured are indeed complying with the new regulation of $0.1 \%$ sulfur fuel content. Compliance has dropped slightly compared to the value of more than $99 \%$ observed for the $1 \%$ sulfur limit in autumn 2014. It should be noted that the global oil price and thus MGO costs for the necessary sulfur quality in January 2015 was the lowest 
since 2009, which could have a positive influence on the acceptance of the new regulation.

With the described method it is possible to easily and reliably identify those ships that do not comply. It is possible to check $10-40 \%$ of all ships entering and leaving the harbour, depending on wind conditions. This should be interesting to government agencies in charge of the control of the SECAs.

Acknowledgements. The research project which facilitated the reported study was funded in part by the German Federal Maritime and Hydrographic Agency and the University of Bremen. The authors thank the Waterways and Shipping Office Hamburg and the Institute for Hygiene and Environment, Hamburg, for their help and support.

The article processing charges for this open-access publication were covered by the University of Bremen.

Edited by: R. Harley

\section{References}

Agrawal, H., Welch, W. A., Miller, J. W., and Cocker, D. R.: Emission measurements from a crude oil tanker at sea, Environ. Sci. Technol., 42, 7098-7103, 2008.

Agrawal, H., Eden, R., Zhang, X., Fine, P. M., Katzenstein, A., Miller, J. W., Ospital, J., Teffera, S., and Cocker, D. R.: Primary Particulate Matter from Ocean-Going Engines in the Southern California Air Basin, Environ. Sci. Technol., 43, 5398-5402, 2009.

Balzani Lööv, J. M., Alfoldy, B., Gast, L. F. L., Hjorth, J., Lagler, F., Mellqvist, J., Beecken, J., Berg, N., Duyzer, J., Westrate, H., Swart, D. P. J., Berkhout, A. J. C., Jalkanen, J.-P., Prata, A. J., van der Hoff, G. R., and Borowiak, A.: Field test of available methods to measure remotely $\mathrm{SO}_{x}$ and $\mathrm{NO}_{x}$ emissions from ships, Atmos. Meas. Tech., 7, 2597-2613, doi:10.5194/amt-7-2597-2014, 2014.

Beecken, J., Mellqvist, J., Salo, K., Ekholm, J., and Jalkanen, J.P.: Airborne emission measurements of $\mathrm{SO}_{2}, \mathrm{NO}_{x}$ and particles from individual ships using a sniffer technique, Atmos. Meas. Tech., 7, 1957-1968, doi:10.5194/amt-7-1957-2014, 2014.

Beecken, J., Mellqvist, J., Salo, K., Ekholm, J., Jalkanen, J.-P., Johansson, L., Litvinenko, V., Volodin, K., and Frank-Kamenetsky, D. A.: Emission factors of $\mathrm{SO}_{2}, \mathrm{NO}_{x}$ and particles from ships in Neva Bay from ground-based and helicopter-borne measurements and AIS-based modeling, Atmos. Chem. Phys., 15, 52295241, doi:10.5194/acp-15-5229-2015, 2015.

Beecken, J.: Remote Measurements of Gas and Particulate Matter Emissions from Individual Ships, $\mathrm{PhD}$ thesis, Chalmers University of Technology, Gothenburg, Sweden, 2015.
Cooper, D. A.: Exhaust emissions from ships at berth, Atmos. Environ., 37, 3817-3830, 2003.

Corbett, J. J., Fischbeck, P. S., and Pandis, S. N.: Global nitrogen and sulphur inventories for oceangoing ships, J. Geophys. Res.Atmos., 104, 3457-3470, 1999.

Corbett, J. J., Winebrake, J. J., Green, E. H., Kasibhatla, P., Eyring, V., and Lauer, A.: Mortality from Ship Emissions: A Global Assessment, Environ. Sci. Technol., 41, 8512-8518, 2007.

Diesch, J.-M., Drewnick, F., Klimach, T., and Borrmann, S.: Investigation of gaseous and particulate emissions from various marine vessel types measured on the banks of the Elbe in Northern Germany, Atmos. Chem. Phys., 13, 3603-3618, doi:10.5194/acp-133603-2013, 2013.

Endresen, Ø., Sørgård, E., Sundet, J. K., Dalsøren, S. B., Isaksen, I. S. A., Berglen, T. F., and Gravir, G.: Emissions from International Sea Transportation and Environmental Impact, J. Geophys. Res.Atmos., 108, 4560, doi:10.1029/2002JD002898, 2003.

Eyring, V., Isaksen, I. S. A., Berntsen, T., Collins, W. J., Corbett, J. J., Endresen, Ø., Grainger, R. G., Moldanova, J., Schlager, H., and Stevenson, D. S.: Transport Impacts on Atmosphere and Climate: Shipping, Atmos. Environ., 44, 4735-4771, doi:10.1016/j.atmosenv.2009.04.059, 2010.

Jiang, L., Kronbak, J., and Christensen, L. P.: The costs and benefits of sulphur reduction measures: Sulphur scrubbers versus marine gas oil, Transport. Res. D-Tr. E, 28, 19-27, 2014

Lauer, A., Eyring, V., Hendricks, J., Jöckel, P., and Lohmann, U.: Global model simulations of the impact of ocean-going ships on aerosols, clouds, and the radiation budget, Atmos. Chem. Phys., 7, 5061-5079, doi:10.5194/acp-7-5061-2007, 2007.

Matthias, V., Bewersdorff, I., Aulinger, A., and Quante, M.: The contribution of ship emissions to air pollution in the North Sea regions, Environ. Pollut., 158, 2241-2250, 2010

Moldanova, J., Fridell, E., Popovicheva, O., Demirdjian, B., Tishkova, V., Faccinetto, A., and Focsa, C.: Characterisation of particulate matter and gaseous emissions from a large ship diesel engine, Atmos. Environ., 43, 2632-2641, 2009.

Reynolds, K. J.: Exhaust gas cleaning systems selection guide. Ship operations cooperative program, The Glosten Associates, USA, 2011.

Schlager, H., Baumann, R., Lichtenstern, M., Petzold, A., Arnold, F., Speidel, M., Gurk, C., and Fischer, H.: Aircraft-based Trace Gas Measurements in a Primary European Ship Corridor, proceedings TAC-Conference, 83-88, 2006.

Sinha, P., Hobbs, P. V., Yokelson, R. J., Christian, T. J., Kirchstetter, T. W., and Bruintjes, R.: Emissions of trace gases and particles from two ships in the southern Atlantic Ocean, Atmos. Environ., 37, 2139-2148, 2003.

UNCTAD RMT, United Nations Conference on Trade and Development, Review of Maritime Transport, 2014.

Williams, E. J., Lerner, B. M., Murphy, P. C., Herndon, S. C., and Zahniser, M. S.: Emissions of $\mathrm{NO}_{x}, \mathrm{SO}_{2}, \mathrm{CO}$, and $\mathrm{HCHO}$ from commercial marine shipping during Texas Air Quality Study (TexAQS) 2006, J. Geophys. Res. Atmos., 114, D21306, doi:10.1029/2009JD012094, 2009. 